\title{
Fuga hacia dentro: Las otras lecturas de la tradición y la ruptura
}

\author{
Raúl Serrano Sánchez \\ Universidad Andina Simón Bolívar, Sede Ecuador \\ raul.serrano@uasb.edu.ec
}

Recibido: 11 - noviembre-2018 / Aceptado: 21 -diciembre-2018

\section{Resumen}

En este texto el autor se propone establecer algunos puntos de convergencia que el libro de Alicia Ortega, Fuga hacia dentro (Buenos Aires, 2017) propone. Se destaca lo que tanto en la primera parte del estudio resulta relevante para la autora, que básicamente se ocupa de lo que es el legado del siglo XIX y los textos que tanto del costumbrismo como del realismo se convertirán en gravitantes para los narradores de la Generación del 30 del siglo posterior. Luego está lo que es mirar los momentos, títulos y autores de la segunda parte del siglo XX, en el que aún suena, están presentes ciertos debates y concepciones que se generaron en el período más rico y fundacional de la literatura de vanguardia en el Ecuador: la década del 30.

Palabras clave: narrativa, Ecuador, costumbrismo, tradición, ruptura, realismo, vanguardia, siglo $\mathrm{XX}$.

\section{Abstract}

In this text the author proposes to establish some points of convergence that the book by Alicia Ortega, Fuga hacia dentro (Buenos Aires, 2017) proposes. What is highlighted in the first part of the study is relevant for the author, who basically deals with what is the legacy of the nineteenth century and the texts that both costumbrismo and realism will become gravitates for the narrators of 
the Generation from the 30th of the following century. Then there is what it is to look at the moments, titles and authors of the second part of the 20th century, in which it still sounds, there are certain debates and conceptions that were generated in the richest and foundational period of avant-garde literature in Ecuador: the 30s.

Keywords: narrative, Ecuador, costumbrismo, tradition, rupture, realism, avantgarde, twentieth century. 
$F$ ga hacia dentro. La novela ecuatoriana en el siglo XX. Filiaciones y memoria de la crítica literaria ${ }^{1}$ (2017) de la académica y ensayista Alicia Ortega Caicedo, es un notable y lúcido estudio que se propone examinar, a partir de un corpus constituido por 39 novelas de autores y autoras ecuatorianas del siglo pasado, los diversos momentos, tendencias y giros que la novelística nuestra ha enfrentado en diferentes etapas de su devenir. Un devenir en el que está inscrita la crítica, ejercida en algunos de los casos por ciertos autores como los de la década del 30 (Alfredo Pareja Diezcanseco, José de la Cuadra, Joaquín Gallegos Lara y Ángel F. Rojas), que en paralelo también desplegaron-ocurrirá lo mismo posteriormente- un importante y fundamental trabajo novelístico.

Varias son las preguntas que Ortega se plantea en este amplio estudio, y quizás la búsqueda de unas posibles respuestas, no siempre conclusivas ni cerradas, son el mayor desafío que entrañan estas páginas. Esas preguntas parten por desempolvar, lo que es todo un descubrimiento, aquellos debates que se dieron entre los intelectuales y creadores luego del proceso inaugurado con la Revolución Liberal de 1895, que se convierte en un parteaguas para quienes integraban la escena cultural de finales del siglo XIX e inicios del nuevo. Período en el que emerge, entre el costumbrismo, una expresión clave para lo que se daba y sobrevendría poco tiempo después: el realismo, que Ortega lo examina a la luz de las "cosas de la tierra" de José Antonio Campos; otro relato pionero, dentro de esta tesitura, es La mala hora, de Leopoldo Benites Vinueza, hasta llegar a dos textos que se encuentran y desencuentran: $A$ la costa, la novela inaugural de Luis A. Martínez y el cuento El guaraguao, uno de los textos más desconcertantes y conmovedores de Gallegos Lara. Trabajos en los que temas como la búsqueda de lo nacional a través de una cultura que exprese, sin muchas diferencias, los matices, las paradojas y contradicciones de una sociedad que estas historias examinan en claves y ciframientos que se transforman en los primeros indicios de una modernidad que con el advenimiento de las vanguardias tendrá plena irradiación. Momento que Ortega disecciona en el capítulo "Novelistas y críticos literarios en la primera mitad del siglo XX". Arranca con el examen de lo que son las "Novelas de la tierra" y cómo dentro del marco latinoamericano esos textos dialogan con los que corresponden a esta instancia y que son los de algunos autores de la Generación del 30 como José de la Cuadra, Demetrio Aguilera Malta, Enrique Gil Gilbert y Ángel F. Rojas.

Los relatos de estos autores sin duda son parte y expresión de la vanguardia andina y latinoamericana que se produce entre la década del 30 hasta mediados del 40, a los que Ortega vuelve, considerando lo que la crítica canónica ha trazado sobre

1 Alicia Ortega Caicedo, Fuga hacia dentro. La novela ecuatoriana en el siglo XX. Filiaciones y memoria de la crítica literaria (Buenos Aires, Corregidor/Universidad Andina Simón Bolívar, Sede Ecuador, 2017, 487 pp.). Este libro obtuvo el Premio Nacional de Ciencias Sociales Isabel Tobar Guarderas 2018, otorgado por el Municipio del Distrito Metropolitano de Quito. 
ellos para interpelarlos desde lo que son las nuevas sensibilidades y percepciones de los tiempos y vientos de la posmodernidad, por tanto, las nuevas claves y estrategias de análisis y lectura. De ahí que su examen no se quede en el recuento sino en la resignificación, por tanto, la reinterpretación de estos textos fundamentales de nuestra tradición a los que hay que sumar (Ortega los ubica en la sección "Retórica del mestizaje: Estéticas indigenistas y posindigenistas"), Huasipungo y otras novelas de J. Icaza, más Los hijos (1962), de Alfonso Cuesta y Cuesta; Porqué se fueron las garzas (1979), de Gustavo Alfredo Jácome, y Bruna, soroche y los tíos (1973), de Alicia Yánez Cossío.

Hay que subrayar que como parte de las "filiaciones y memoria de la crítica literaria", Ortega nos ofrece las diversas posturas de los críticos y ensayistas que emergen en cada uno de estos períodos. De ahí que nos participe de lo que son los planteamientos de molde eurocéntrico e hispánico en Gonzalo Zaldumbide, Augusto Arias, Remigio Crespo Toral y el padre Aurelio Espinosa Pólit, pasando por los hermeneutas de la nueva literatura que se gesta en la década del 30, a los que se identifica como parte de la "crítica nacionalista": A. F. Rojas y Benjamín Carrión, hasta desembocar en la crítica - desde la sociología de la literatura- de Agustín Cueva, Alejandro Moreano, Fernando Tinajero y otros como Miguel Donoso Pareja, para quien, en las últimas décadas del siglo XX, va a contar y pesar "la hora del texto".

En la segunda parte del estudio, que considera los textos que circulan desde la década del 40-50 hasta finales del siglo XX, Ortega los examina considerando lo que son las búsquedas, las construcciones de nuevos abordajes y motivos dentro de los proyectos narrativos de algunos de los autores de la tradición de la ruptura como Gallegos Lara, Pareja Diezcanseco y los nuevos nombres y voces que se suman, dentro de esa línea de ruptura, con esas preguntas perturbadoras que los procesos de modernidad a los que se verá sometida la sociedad y la cultura del país, les formulan a los narradores Pedro J. Vera, Arturo Montesinos Malo, Alejandro Carrión y César Dávila Andrade (de la llamada transición que se opera en la década de los 50). Transición que dará paso a la década siguiente en la que el tablero se verá alterado por los sucesos internacionales (la Revolución cubana, las luchas anticolonialistas en África, Mayo del 68, la contracultura en Estados Unidos, etc.), por lo que la literatura y la política agitacional tendrá sus rituales desde las propuestas parricidas de los tzántzicos y la crítica cultural y literaria de filiación marxista de Agustín Cueva.

Fuga hacia dentro se cierra, en este segundo momento, con los subcapítulos: "Aventura intelectual y novelística. Segunda mitad del siglo XX" y "La última década del siglo XX: Encuentro y desencuentros del sujeto con la historia”. En el primero, Ortega pasa revista a un par de novelas centrales publicadas en la década del 70 (Entre Marx y una mujer desnuda de Adoum y Polvo y ceniza de Eliécer Cárdenas), en las que repara en lo que denomina "Conciencia intelectual e inspiración revolucionaria". En relación al "desencanto y la experiencia del fracaso", a los autores de este periodo los hace converger con lo que es la "década perdida" (según los brujos 
del neoliberalismo) de los 80. Los textos de los 70-80, la estudiosa los desmonta desde lo que considera son las "Modalidades de la conciencia cínica y la afirmación festiva": Ciudad de invierno (1979), Sueños de lobos (1986), de Abdón Ubidia; Nunca más el mar (1981) de Miguel Donoso Pareja; El rincón de los justos (1983), de Jorge Velasco Mackenzie y La cofradia del mullo del vestido de la virgen pipona (1985), de Alicia Yánez Cossío. En lo relacionado al momento final, la crítica se concentra en lo que son los "Encuentros y desanclajes del sujeto con la historia".

Resulta muy reveladora la manera en la que Ortega titula cada acápite dedicado a las "novelas de los 90": Azulinaciones (1990) de Natasha Salguero. Des-aprendizajes y afirmación femenina; El devastado jardín del paraiso (1990) de Alejandro Moreano. Encuentro del sujeto con la historia; El otro lado de las cosas, de Francisco Proaño Arandi. Ocupación del espacio, fratricidio, la memoria que sobreviene; Resígnate a perder (1998) de Javier Ponce. Violencia, culpa, deseo homosexual; El viajero de Praga (1996) de Javier Vásconez. Exilio interior y desanclaje de la historia; Crisis de masculinidad, sujeto letrado y humor. El deseo que lleva tu nombre (1989) y Una niña adorada (1993) de Carlos Carrión; Interpelaciones al presente. Hoy empiezo a acordarme (1994) de Miguel Donoso Pareja; Ciudad sin ángel, de Jorge Enrique Adoum. Acoso textual (1999) de Raúl Vallejo".

Descriptores y guiños que establecen de manera ágil y acertada las señas particulares con las que la crítica construye entradas para desmontar la máquina de sentidos que cada uno de estos textos propone. No hay duda que no se trata de un inventario que clausure las posibilidades de incorporar a otros autores y autoras cuya obra, dentro de este periodo, es muy significativa.

En las conclusiones, Ortega retoma algunos de los elementos que se han diseminado en todo su libro. Centra su discusión en destacar aquella pregunta que tiene que ver con "¿desde dónde nos leemos?”; confronta algunas visiones críticas, polémicas, que parten por reivindicar la libertad del escritor ante ciertas "cargas" como lo identitario y la relación con lugar de origen; o esas diversas aperturas que la narrativa vanguardista de Palacio desata y que se contraponen a los postulados del realismo limitado y limitante, supuestamente, de Icaza, cuya obra también coparticipa de todo lo que es la revuelta vanguardista de los 30. En su reflexión, Ortega contrapone a esos planteamientos lo expuesto por el crítico Alejandro Moreano en su ensayo "Entre la permanencia y el éxodo" (2008), en el que trata sobre el "llamado a romper con la Generación del 30 como un matricidio", formulado por algunos escritores de las nuevas generaciones quienes dialécticamente buscan poner en cuestionamiento aquellos discursos con los que no tienen ningún tipo de convergencia. Otro aspecto en el que la autora insiste, es el de desmitificar la idea, manejada sobre todo por los escritores de los 70 y 80 , respecto a convertir a Palacio y su obra como un único referente de la modernidad de nuestra literatura; pero, como bien anota Ortega: "Una tradición literaria se empobrece cuando se busca construir su canon a partir del reconocimiento de un 'guía', en singular". 
Además, en este cierre se pasa revista a otras posturas que van desde lo eurocéntrico, las debilidades coloniales y poscoloniales de algunos críticos y escritores quienes en pos de la universalidad olvidan -lo señaló en su momento el maestro José de la Cuadra- que la aldea que habitan es su universo; posturas que Ortega rebate con argumentos que ratifican que Fuga hacia dentro es un libro que abre y reabre la reflexión y el análisis crítico, siempre necesario en torno a la tradición y las rupturas que se han operado, tanto en nuestra narrativa como desde las concepciones críticas en un país donde los permanentes lamentos de que "no tenemos crítica" nos ponen ante la idea de cuán necesario es continuar y ahondar en esa "fuga hacia dentro", en ese, como diría Lezama Lima, volver a "los orígenes". Una "fuga" que este documentado libro de Ortega explora entre una y otra etapa del siglo XX; texto que se inserta por derecho propio dentro de lo que es la constelación de títulos fundacionales de la crítica nacional como La novela ecuatoriana (1948) de Ángel F. Rojas, El nuevo relato ecuatoriano (1951) de Benjamín Carrión y Los grandes de la década del 30 (1985) de Miguel Donoso Pareja.

Le sobra razón a la autora cuando señal que "Es tarea de la crítica devolver el hecho estético a su ámbito original, en el que coinciden lo cognitivo, lo ético-político y lo estético". Pues esa premisa se cumple a cabalidad en este estudio que, a la vez, es parte de un redescubrimiento que a propios y extraños dejará repletos de preguntas y revelaciones que los motivará, si no lo ha hecho ya, a buscar y adentrarse en todos los textos que se exploran en este viaje alucinante por las encrucijadas de la novelística y los avatares de la crítica ecuatoriana del siglo XX que, valga anotarlo, sin renunciar al rigor académico, nunca se atenta contra la intensidad y fluidez de la escritura. Vitales en la práctica del ensayo y la crítica actuales.

(Quito, diciembre 2019). 